\title{
REDUÇÃO DAS EMISSÕES DE POLUENTES VEICULARES NAS REGIÕES METROPOLITANAS DE SÃO PAULO, CONSIDERANDO RENOVAÇÕES DE FROTA CIRCULANTE, NO ANO DE 2016
}

\author{
Cristiane Dias ${ }^{1}$, Marcelo Pereira Bales ${ }^{1}$, Silmara Regina da Silva ${ }^{1}$ e Liliana \\ José Barbosa ${ }^{1}$ \\ ${ }^{1}$ CETESB (Companhia Ambiental do Estado de São Paulo) \\ E-mails: cdias@sp.gov.br, mbales@sp.gov.br, silmsilva@sp.gov.br
}

\section{RESUMO}

Atualmente, os inventários de fontes de poluição atmosférica têm destacado a importância das fontes móveis nas emissões de poluentes locais e de gases de efeito estufa, nas áreas urbanas e em suas regiões metropolitanas. Este trabalho apresenta as emissões veiculares na Macrometrópole Paulista e na região metropolitana de São Paulo, considerando o período de 2006 a 2016. Foram indicadas as estimativas com as frotas circulantes totais e com novas configurações de frota, tais como: com a troca de caminhões de mais de 20 anos por caminhões novos, com a troca de ônibus urbanos e micro-ônibus com mais de 10 anos por ônibus novos e a troca de automóveis com mais de 30 anos por veículos elétricos, no ano de 2016. Os poluentes considerados foram o monóxido de carbono, os óxidos de nitrogênio, o material particulado, os hidrocarbonetos não metano, o dióxido de carbono equivalente e os compostos orgânicos voláteis. Para os veículos pesados, os resultados indicam que com a troca de caminhões com mais de 20 anos, pode-se reduzir cerca de 8.311 toneladas de $\mathrm{NO}_{x}$ na Macrometrópole e 3.881 toneladas de $\mathrm{NO}_{\mathrm{x}}$ na região metropolitana de São Paulo. E para os veículos leves, com a troca de automóveis com mais de 30 anos por veículos elétricos, podese reduzir cerca de 16.021 toneladas de $\mathrm{CO}$ e 3.248 toneladas de COV na Macrometrópole em 2016.

\section{INTRODUÇÃO}

Os inventários de fontes de poluição atmosférica pretendem identificar e quantificar as emissões de poluentes atmosféricos presentes em uma determinada área ou região, em um determinado período de tempo. Diversas são as fontes de poluição que devem ser estudadas na elaboração de um inventário de fontes, dentre elas pode-se destacar: 
1. Fontes pontuais, como as instalações industriais;

2. Fontes área: fontes de poluição restritas a determinadas áreas, como pequenos empreendimentos, armazenamento de combustíveis, etc;

3. Fontes móveis rodoviárias, ou os veículos (automóveis, comerciais leves ciclo Otto e Diesel, motocicletas, ônibus e caminhões, em suas diversas sub-categorias);

4. Fontes móveis não rodoviárias, como equipamentos de construção, de corte de grama, da área rural, etc; e

5. Fontes biogênicas, como as emissões de hidrocarbonetos por organismos vivos, provenientes de florestas, por exemplo.

Os inventários de fontes de poluição atmosférica fornecem dados para os estudos de monitoramento da qualidade do ar porque a qualidade do ar é diretamente influenciada pela distribuição e intensidade das emissões de poluentes atmosféricos de origem veicular e industrial [1].

A qualidade do ar nas cidades e regiões metropolitanas tem chamado a atenção da população e dos órgãos governamentais devido ao lançamento de poluentes com alta toxicidade na atmosfera, que geralmente têm origem em atividades antrópicas, como nas atividades industriais e nos meios de transporte.

Muitos estudos são publicados ao redor do mundo, com enfoque nas fontes móveis. O desenvolvimento econômico e o crescimento da frota veicular de algumas regiões dos Estados Unidos ou da China, por exemplo, têm despertado o interesse de diversos grupos de pesquisa e de órgãos governamentais para o desenvolvimento de políticas públicas que possam resultar na melhoria da qualidade do ar das grandes cidades e regiões metropolitanas.

A figura 1 apresenta a diminuição da expectativa de vida da população européia no ano 2000 (à esquerda) causada pela exposição ao material particulado fino $\left(\mathrm{MP}_{2,5}\right) \mathrm{e}$ o cenário proposto para o ano de 2020 (à direita), após a implantação de ações e programas para a mitigação das emissões de poluentes atmosféricos.

Pode-se destacar o material particulado como um dos poluentes causadores de graves efeitos adversos à saúde, quando a população é intensivamente exposta. E é fundamental caracterizar as fontes de poluição existentes nas áreas urbanas para a elaboração de políticas públicas eficazes.

No Reino Unido, há um plano governamental para a proibição da venda de automóveis novos e comerciais leves que usam diesel e gasolina como combustíveis a partir de 2040, com o propósito de melhorar a qualidade do ar das cidades. Como a tecnologia de carros elétricos e híbridos está em aperfeiçoamento, os governos estão definindo suas metas de investimentos de longo prazo em novas tecnologias veiculares e infraestrutura, por exemplo. 
Figura 1. Diminuição da expectativa de vida no continente europeu, no ano 2000 (à esquerda) devido à exposição ao poluente material particulado fino $\left(\mathrm{MP}_{2,5}\right)$ de emissões antropogênicas e cenário possível em 2020.
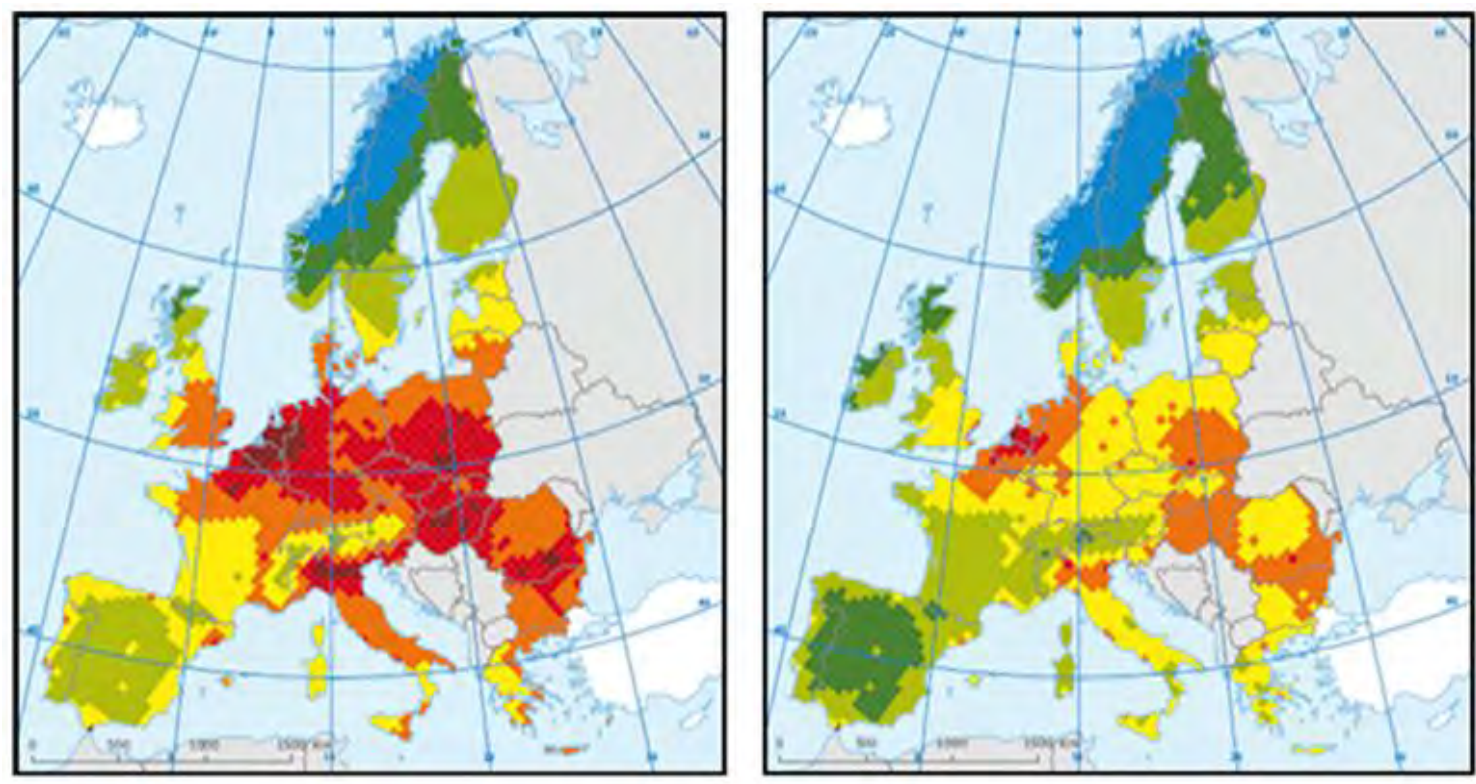

Estimated losses in life expectancy attributable to exposure to fine particulate matter $\left(\mathrm{PM}_{2,3}\right)$ from anthropogenic emissions for 2000 (left) and 2020 (right)

Months

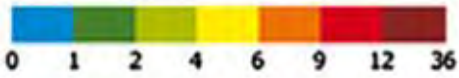

No data

Outside study area

Fonte:[2] Monks, P. S. et al (2009)

Com o objetivo de reduzir as emissões de poluentes veiculares e em se tratando de programas de renovação de frota, a Desenvolve SP, a Agência de Desenvolvimento do Governo do Estado de São Paulo, publicou o Programa de Incentivo à Renovação de Frota de Caminhões [3]. Este programa visa à troca de caminhões com mais de 30 anos por veículos novos, com ganhos ambientais e redução dos acidentes envolvendo estes veículos. Com subsídios governamentais, os veículos antigos precisam ser entregues à reciclagem.

Ainda considerando o estado de São Paulo, a lei ${ }^{\circ} 15.831$ de 15 de junho de 2015 [4] disciplina nos contratos de concessão a idade média da frota de ônibus, miniônibus e micro-ônibus que operam no Sistema de Transporte Coletivo Urbano de Caráter Metropolitano; estabelecendo o parâmetro de 4 a 6 anos para a idade média dos veículos.

Dentre as regiões metropolitanas e aglomerações urbanas do estado de São Paulo, a região metropolitana de São Paulo (RMSP) apresenta um alto potencial de formação de ozônio, dado que há grande emissão de seus precursores, 
principalmente de origem veicular, porém sua ocorrência em maior ou menor frequência está relacionada às variações das condições meteorológicas, uma vez que as variações quantitativas nas emissões de seus precursores são pequenas de ano a ano. Pode-se acrescentar que em função das complexas interações químicas e meteorológicas envolvidas nas reações atmosféricas de formação e transporte do ozônio, não é possível observar uma tendência na concentração deste poluente ao longo dos anos [1], [5].

As estimativas de emissões veiculares publicadas anualmente pela CETESB são determinadas de acordo com as metodologias publicadas nas duas edições do Inventário Nacional de Emissões Atmosféricas por Veículos Automotores Rodoviários [6], [7] e pelo Painel Intergovernamental de Mudanças Climáticas [8]. Essas metodologias demonstram que as emissões veiculares são fundamentalmente dependentes dos fatores de emissão, da intensidade de uso ou quilometragem anual do veículo e do consumo de combustíveis da área ou região de interesse.

O objetivo deste trabalho é apresentar as emissões veiculares estimadas para as maiores regiões metropolitanas do estado de São Paulo, no ano de 2016, com a inclusão de novas configurações, como a substituição de veículos mais antigos (como caminhões com mais de 20 e 30 anos, e ônibus urbanos e micro-ônibus com mais de 10 anos) por veículos novos e com novas tecnologias de controle de emissões; assim como a eliminação de automóveis com mais de 30 anos de uso, trocados por veículos elétricos, por exemplo.

\section{INFORMAÇÕES GERAIS}

A Macrometrópole Paulista e as regiões metropolitanas de São Paulo, devido à intensa atividade veicular e ao grande número de habitantes, concentram a maior parte das emissões de poluentes veiculares e de gases de efeito estufa (GEE) do estado de São Paulo.

A figura 2 demonstra a evolução das emissões de monóxido de carbono (CO) e de hidrocarbonetos não metano (NMHC total) no estado de São Paulo, no período de 2006 a 2016, na Macrometrópole Paulista e nas regiões metropolitanas de São Paulo e de Campinas.

Pode-se observar que a Macrometrópole Paulista representa em média $68 \%$ das emissões de CO obtidas no estado de São Paulo e 69\% em média das emissões de NMHC, no período de 2006 a 2016. A região metropolitana de São Paulo apresentou em média $40 \%$ das emissões de CO totalizadas no estado de São Paulo, e $30 \%$ das emissões de NMHC total E a região metropolitana de Campinas indicou em média $8 \%$ das emissões de $\mathrm{CO}$ e NMHC total, no período. 
De modo geral, a figura 2 indica a redução das emissões veiculares no período analisado. Estes resultados podem ser atribuídos às ações e programas do PROCONVE/PROMOT e da renovação natural da frota circulante. O Programa de Controle da Poluição do Ar por Veículos Automotores (PROCONVE/PROMOT) foi inicialmente elaborado em 1986 pelo Conselho Nacional do Meio AmbienteCONAMA 18/86. Desde então, o programa tem alcançados resultados mensuráveis e objetivos. O Programa tem como principal meta a "redução dos níveis de emissão de poluentes nos veículos automotores além de incentivar o desenvolvimento tecnológico nacional, tanto na engenharia automotiva, como em métodos e equipamentos para a realização de ensaios e medição de poluentes" [9].

Figura 2. Evolução das emissões de $\mathrm{CO}$ e $\mathrm{NMHC}$ total, no estado de São Paulo (ESP), na Macrometrópole Paulista (MM), na região metropolitana de São Paulo (RMSP) e de Campinas (RMC), de 2006 a 2016.

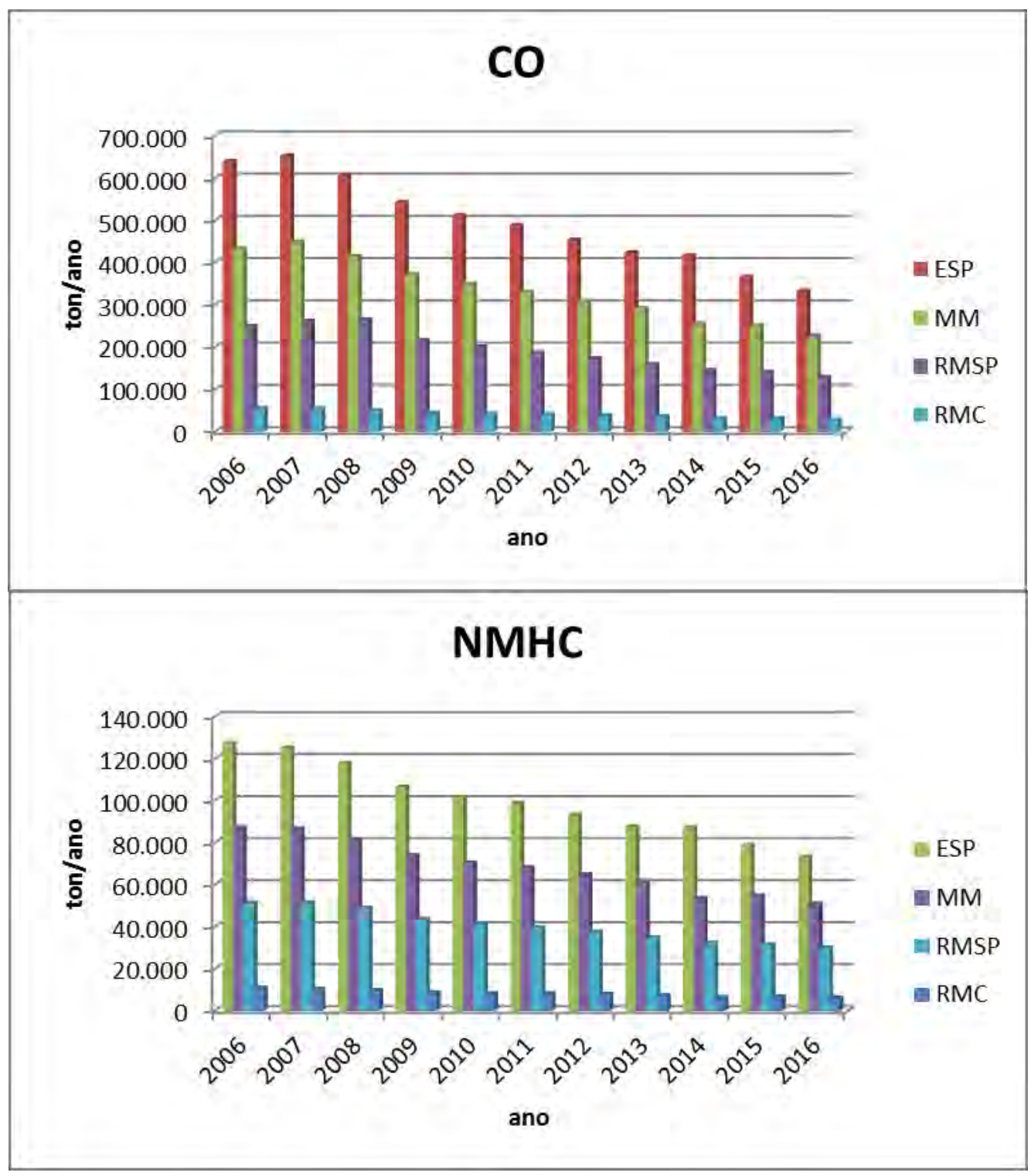

Fonte: [5] CETESB (2017) 
A figura 3 apresenta a evolução das emissões de material particulado (MP) e de óxidos de nitrogênio $\left(\mathrm{NO}_{\mathrm{x}}\right)$ no estado de São Paulo, na Macrometrópole Paulista e nas regiões metropolitanas de São Paulo e de Campinas, no período de 2006 a 2016. Pode-se observar que a Macrometrópole Paulista representa em média $56 \%$ das emissões de MP obtidas no estado de São Paulo e $58 \%$ em média das emissões de $\mathrm{NO}_{x}$, no período de 2006 a 2016. A região metropolitana de São Paulo apresentou em média $29 \%$ das emissões de MP totalizadas no estado de São Paulo, e $28 \%$ das emissões de $\mathrm{NO}_{\mathrm{x}}$. $\mathrm{E}$ a região metropolitana de Campinas indicou em média $8 \%$ das emissões de $\mathrm{MP}$ e $\mathrm{NO}_{\mathrm{x}}$, no período.

Figura 3. Evolução das emissões de material particulado (MP) e $\mathrm{NO}_{x}$, no estado de São Paulo, na Macrometrópole Paulista e em algumas regiões metropolitanas, de 2006 a 2016.

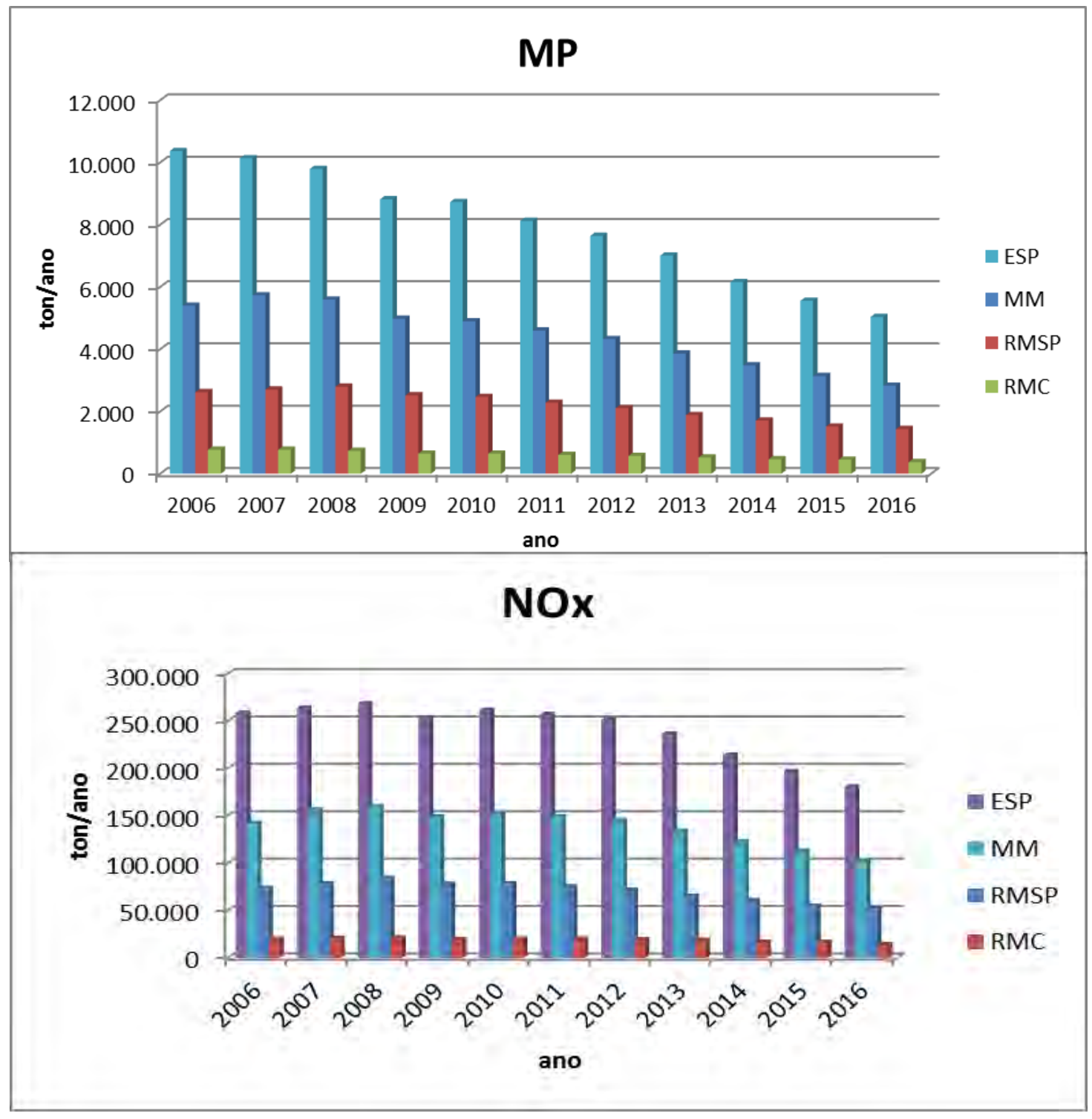

Fonte: [5] CETESB (2017) 
A figura 4 indica a evolução das emissões de hidrocarbonetos não metano de escapamento (NMHC escap) e de hidrocarbonetos não metano evaporativas (NMHC evap) no estado de São Paulo, na Macrometrópole Paulista e nas regiões metropolitanas de São Paulo e de Campinas, no período de 2006 a 2016. Pode-se observar que a Macrometrópole Paulista representa em média $66 \%$ das emissões de hidrocarbonetos não metano de escapamento (NMHC escap) obtidas no estado de São Paulo e $71 \%$ em média das emissões de hidrocarbonetos não metano evaporativas (NMHC evap), no período de 2006 a 2016. A região metropolitana de São Paulo apresentou em média $37 \%$ das emissões de hidrocarbonetos não metano de escapamento (NMHC escap) totalizadas no estado de São Paulo, e $44 \%$ das emissões de hidrocarbonetos não metano evaporativas (NMHC evap). $E$ a região metropolitana de Campinas indicou em média 8\% das emissões de NMHC de escapamento e evaporativas, no período.

Figura 4. Evolução das emissões de NMHC de escapamento e de NMHC evaporativas, no estado de São Paulo, na Macrometrópole e em algumas regiões metropolitanas, de 2006 a 2016.

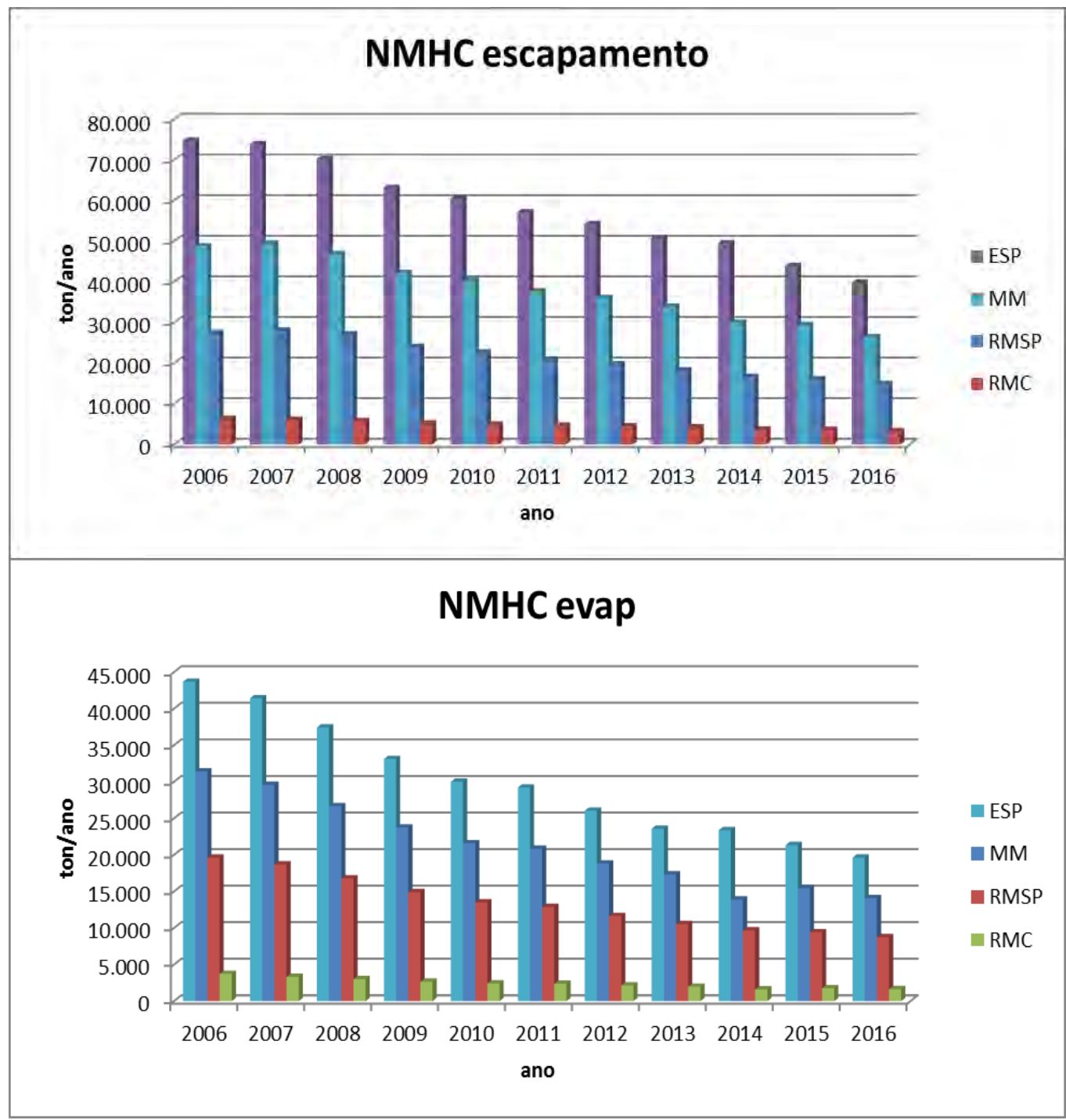

Fonte: [5] CETESB (2017) 
A figura 5 indica a evolução das emissões de hidrocarbonetos não metano de abastecimento (NMHC abastecimento) e de compostos orgânicos voláteis (COV) no estado de São Paulo, na Macrometrópole Paulista e nas regiões metropolitanas de São Paulo e de Campinas, no período de 2006 a 2016. Pode-se observar que a Macrometrópole Paulista representa em média $75 \%$ das emissões de hidrocarbonetos não metano de abastecimento (NMHC abastecimento) obtidas no estado de São Paulo e $69 \%$ em média das emissões de COV, no período de 2006 a 2016. A região metropolitana de São Paulo apresentou em média $47 \%$ das emissões de hidrocarbonetos não metano de abastecimento (NMHC abastecimento) totalizadas no estado de São Paulo, e 40\% das emissões de compostos orgânicos voláteis (COV). E a região metropolitana de Campinas indicou em média 9\% e 8\% respectivamente das emissões de NMHC de abastecimento e de COV, no período em análise.

Figura 5. Evolução das emissões de NMHC de abastecimento e de COV (compostos orgânicos voláteis) no estado de São Paulo, na Macrometrópole e em algumas regiões metropolitanas, de 2006 a 2016.

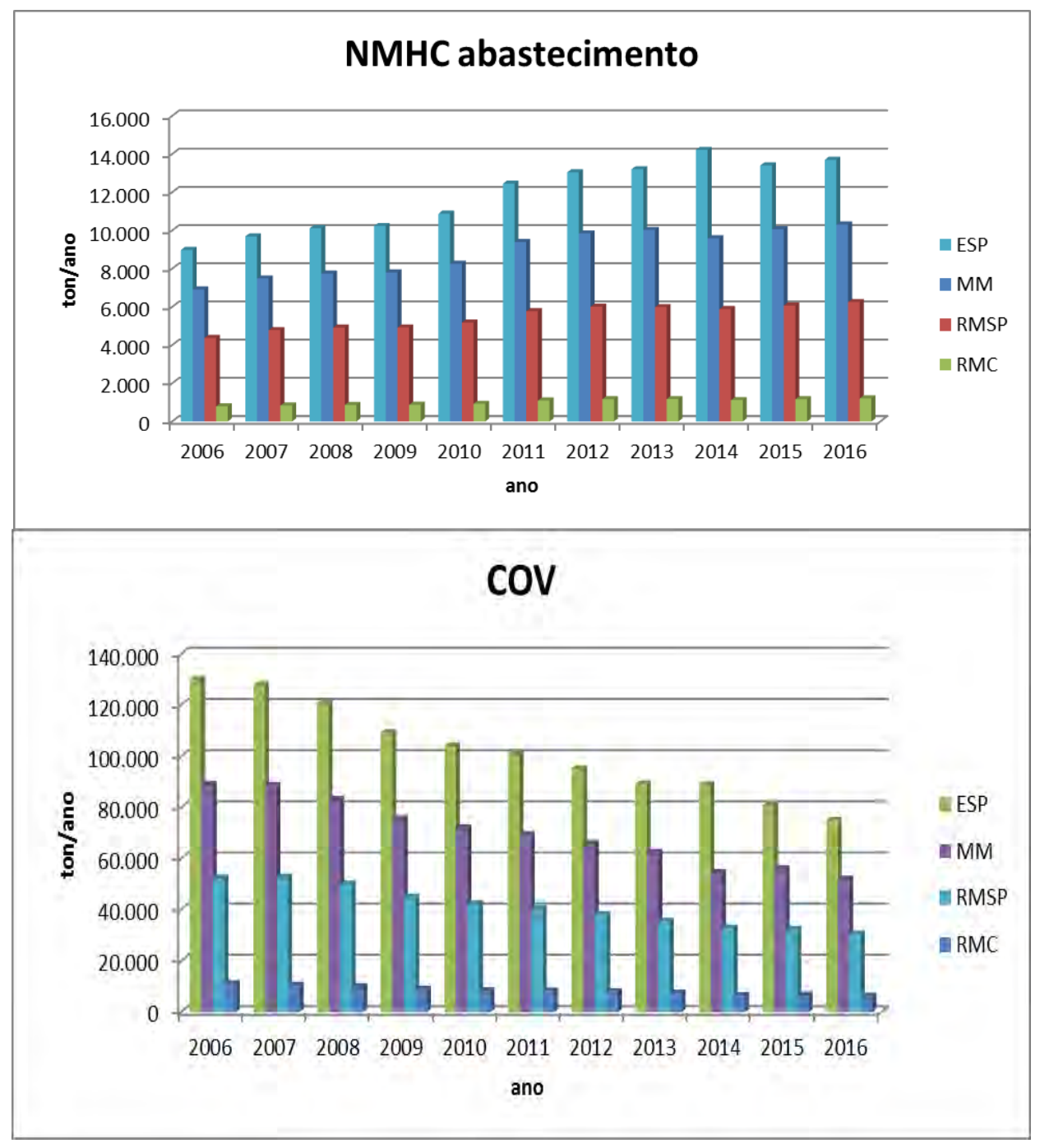

Fonte: [5] CETESB (2017) 
Na figura 5 pode-se observar o crescimento das emissões de abastecimento até o ano de 2014, com pequena queda em 2015 e o retorno do crescimento em 2016. As emissões de abastecimento são calculadas em função do consumo de combustíveis (gasolina $\mathrm{C}$ e etanol hidratado) e não são controladas pelo PROCONVE/PROMOT.

A figura 6 indica a evolução das emissões de dióxido de carbono equivalente $\left(\mathrm{CO}_{2}\right.$ eq) no estado de São Paulo, na Macrometrópole Paulista e nas regiões metropolitanas de São Paulo e de Campinas, no período de 2006 a 2016.

Pode-se observar que a Macrometrópole Paulista representa em média $64 \%$ das emissões de dióxido de carbono equivalente $\left(\mathrm{CO}_{2}\right.$ eq) obtidas no estado de São Paulo, no período de 2006 a 2016. A região metropolitana de São Paulo apresentou em média $35 \%$ das emissões de dióxido de carbono equivalente $\left(\mathrm{CO}_{2}\right.$ eq) totalizadas no estado de São Paulo. E a região metropolitana de Campinas indicou em média $8 \%$ das emissões de dióxido de carbono equivalente $\left(\mathrm{CO}_{2}\right.$ eq), no período em estudo.

Figura 6. Evolução das emissões de dióxido de carbono equivalente no estado de São Paulo, na Macrometrópole e em algumas regiões metropolitanas, de 2006 a 2016.

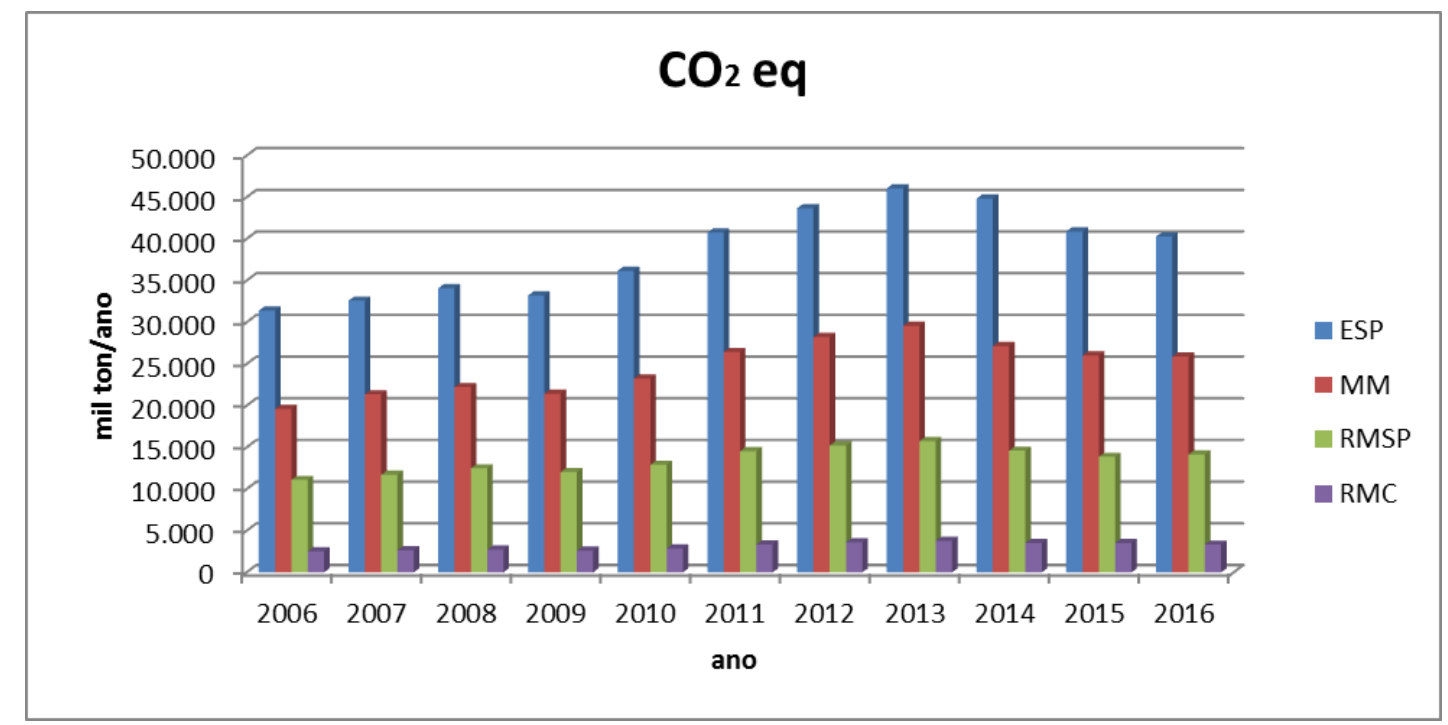

Fonte: [5] CETESB (2017)

As variações das emissões de dióxido de carbono equivalente $\left(\mathrm{CO}_{2}\right.$ eq) dependem diretamente do consumo de combustíveis fósseis (gasolina A e óleo diesel), no período de 2006 a 2016. 


\section{METODOLOGIA}

De maneira abrangente o cálculo é dividido em duas grandes etapas: a primeira consiste na caracterização da frota circulante, envolvendo idade da frota, perfil de sucateamento e consumo do combustível para a correção da intensidade de uso. A segunda etapa, referente ao cálculo efetivo das emissões, considera os fatores de emissão específicos para cada poluente.

Os poluentes considerados são:

$>$ Monóxido de Carbono (CO): para todas as categorias de veículos que usam gasolina comum, etanol hidratado e óleo diesel;

$>$ Hidrocarbonetos não metano (NMHC): para todas as categorias de veículos que usam gasolina comum, etanol hidratado, óleo diesel; e incluem as emissões de escapamento, evaporativas e de abastecimento veicular;

> Óxidos de nitrogênio $\left(\mathrm{NO}_{\mathrm{x}}\right)$ : para todas as categorias de veículos que usam gasolina comum, etanol hidratado e óleo diesel;

> Material particulado (MP): para todas as categorias de veículos que usam os combustíveis gasolina comum e óleo diesel;

$>$ Compostos orgânicos voláteis (COV): incluem os hidrocarbonetos não metano (NMHC) totais e os aldeídos totais ( $\mathrm{RCHO}$ ), para todas as categorias de veículos que usam gasolina comum, etanol hidratado e óleo diesel; e

$>$ Dióxido de Carbono equivalente $\left(\mathrm{CO}_{2}\right.$ eq): composto pelos gases $\mathrm{CO}_{2}$, $\mathrm{CH}_{4}$ e $\mathrm{N}_{2} \mathrm{O}$ ponderados pelo GWP(Potencial de aquecimento global), em um horizonte de 100 anos, para todas as categorias de veículos que usam gasolina comum, etanol hidratado e óleo diesel.

Os combustíveis considerados foram a gasolina comum, o etanol hidratado e o óleo diesel. A gasolina comum tem etanol anidro em sua composição, em percentual definido na legislação variando de $18 \%$ a $27 \%$ em volume. O etanol hidratado possui cerca de $5 \%$ em volume de água em sua composição. O óleo diesel tem de $2 \%$ a $7 \%$ de biodiesel em sua composição, de 2006 a 2016.

Para o cálculo das emissões veiculares é necessário obter dados provenientes de diversas bases de dados como:

1. Licenciamento anual de veículos novos nos últimos 40 anos, da Associação Nacional dos Fabricantes de Veículos Automotores [10].

2. Licenciamento anual de motocicletas novos nos últimos 35 anos, da Associação Brasileira dos Fabricantes de Motocicletas, Ciclomotores, Motonetas, Bicicletas e Similares [11].

3. Consumo anual de gasolina comum, etanol hidratado e óleo diesel, da Agência Nacional do Petróleo, Gás Natural e Biocombustíveis [12], [13].

4. Preços médios anuais de gasolina comum e etanol hidratado, da Agência Nacional do Petróleo, Gás Natural e Biocombustíveis [12].

5. Taxas de sobrevivência de veículos (curvas de sucateamento) [14]. 
6. Intensidade de uso de referência ( $\mathrm{km} / \mathrm{ano}$ ), da Companhia Ambiental do Estado de São Paulo [5].

7. Fatores médios de emissão de veículos novos por categoria, por poluente e por ano de fabricação [5].

8. Dados de autonomia dos veículos por categoria e por ano de fabricação [5], [6].

9. Dados da frota de veículos registrada, por categoria e por ano de fabricação (para o cálculo de emissões de regiões ou de municípios) ([15].

A equação geral de cálculo das emissões veiculares utilizada é a equação 1:

$$
E=F e \times F r \times l u
$$

(equação 1)

Onde:

- E é a taxa anual de emissão do poluente considerado (g/ano);

- Fe é o fator de emissão do poluente considerado. É específico para cada tipo de veículo, idade e combustível utilizado. É expresso em massa de poluentes emitida por quilômetro percorrido $\left(\mathrm{g}_{\text {poluente }} / \mathrm{km}\right)$;

- Fr é a frota de veículos circulante para cada tipo de veículo, idade e combustível considerado. É expressa em número de veículos; e

- lu é a intensidade de uso do veículo. É específico para cada tipo e idade do veículo, expressa em quilometragem anual percorrida (km/ano).

Os fatores de emissão por categoria/combustível e poluente resultam da média ponderada de ensaios de emissões dos modelos de veículos novos mais vendidos, para o acompanhamento do PROCONVE/PROMOT. No caso dos automóveis e comerciais leves do ciclo Otto, os fatores de emissão devem ser corrigidos por curvas de deterioração que incrementam os fatores de emissão, conforme avança a quilometragem acumulada do veículo. Essas curvas dependem também do ano de fabricação do veículo. Há uma curva diferente para cada ano ou intervalo.

A frota em circulação compreende todos os veículos com até 40 anos de fabricação. Para este trabalho, considerou-se que os veículos das frotas circulantes das áreas estudadas se encontram em condições adequadas de manutenção, de acordo com as recomendações dos fabricantes. A figura 7 apresenta a taxa de sobrevivência empregada no cálculo da frota circulante no estado de São Paulo, na Macrometrópole Paulista e nas regiões metropolitanas de São Paulo e Campinas, no período de 2006 a 2016. 
Figura 7. Taxa de sobrevivência dos veículos por categoria, em função da idade até 40 anos.

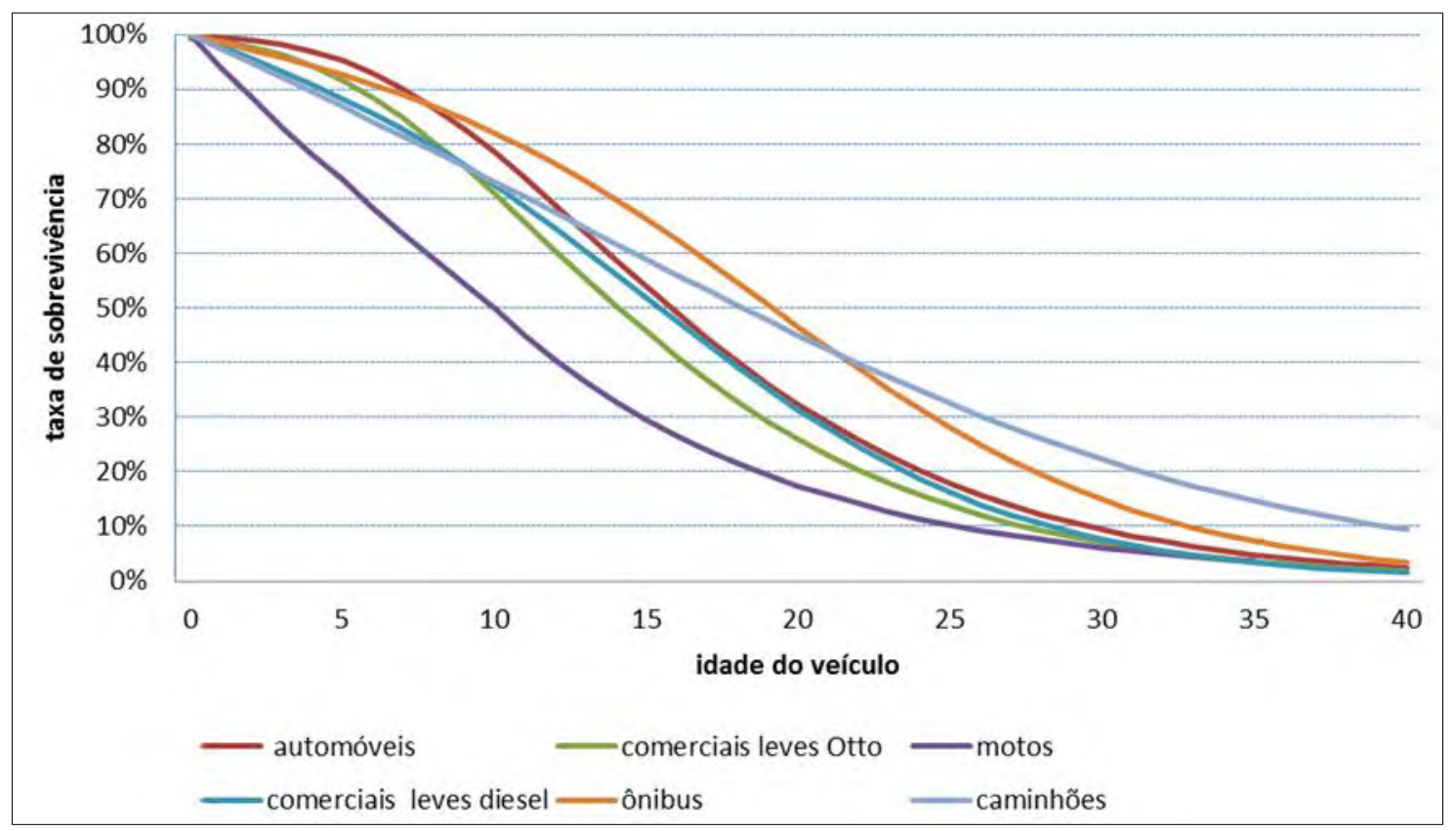

Fonte: [5] CETESB (2017)

A intensidade de uso de referência representa a quilometragem ou a distância percorrida por ano e por tipo de veículo. Esta variável representa uma frota diversificada, onde existem veículos leves e pesados, além de motocicletas, e cada categoria com um perfil próprio de utilização. Desta forma, a variável intensidade de uso de referência precisa ser ajustada em função do consumo de combustíveis observado na região de interesse.

Foram empregadas estimativas de intensidade de uso de referência ou quilometragem anual percorrida por categoria, variando em função da idade do veículo. A partir dos valores de intensidade de uso de referência e do volume de combustíveis consumidos nas Regiões Metropolitanas do Estado de São Paulo foi realizado o ajuste da intensidade de uso ou da quilometragem anual percorrida. 


\section{RESULTADOS E DISCUSSÕES \\ 3.1. Emissões da Macrometrópole Paulista}

Como indica a tabela 1, a Macrometrópole Paulista é um dos maiores aglomerados urbanos do hemisfério sul. Abriga a região metropolitana de São Paulo (RMSP), entre as seis maiores do mundo, segundo a Organização das Nações Unidas (ONU), além das regiões metropolitanas da Baixada Santista, de Campinas, de Sorocaba, do Vale do Paraíba e Litoral Norte, as aglomerações urbanas de Jundiaí e de Piracicaba e a unidade regional Bragantina [16].

Tabela 1. Número de municípios, população e frota circulante no estado de São Paulo, Macrometópole Paulista e região metropolitana de São Paulo, no ano de 2016

\begin{tabular}{llll}
\hline Região & $\begin{array}{l}\text { Número de } \\
\text { municípios }\end{array}$ & população & Frota circulante \\
\hline Estado & 645 & 43.359 .005 & 15.295 .196 \\
Macrometrópole & 174 & 32.376 .430 & 11.522 .527 \\
RMSP & 39 & 20.579 .717 & 7.316 .193 \\
\hline
\end{tabular}

Fonte: [5] CETESB (2017)

A tabela 2 apresenta as reduções de emissões de poluentes veiculares no ano de 2016, na Macrometrópole Paulista. Foram estimadas as reduções das emissões de monóxido de carbono (CO), hidrocarbonetos não metano de escapamento (NMHC escapamento), hidrocarbonetos não metano evaporativas (NMHC evaporativa), hidrocarbonetos não metano de abastecimento (NMHC abastecimento), hidrocarbonetos não metano totais (NMHC total), óxidos de nitrogênio $\left(\mathrm{NO}_{\mathrm{x}}\right)$, material particulado (MP), dióxido de carbono equivalente $\left(\mathrm{CO}_{2}\right.$ eq) e compostos orgânicos voláteis (COV).

Tabela 2. Reduções das emissões de poluentes veiculares da Macrometrópole Paulista em 2016, devido a renovações de frota circulante.

\begin{tabular}{|c|c|c|c|}
\hline poluente (ton) & $\begin{array}{c}\text { Macrometrópole Paulista } \\
\text { Redução das emissões com a } \\
\text { troca de caminhões de mais de } \\
20 \text { anos }\end{array}$ & $\begin{array}{c}\text { Macrometrópole Paulista } \\
\text { Redução das emissões com a } \\
\text { troca de ônibus urbanos e micro- } \\
\text { ônibus com mais de 10 anos }\end{array}$ & $\begin{array}{c}\text { Macrometrópole Paulista } \\
\text { Redução das emissões com a } \\
\text { retirada de automóveis com } \\
\text { mais de } 30 \text { anos da frota } \\
\text { circulante }\end{array}$ \\
\hline CO & 1.503 & 1.118 & 16.021 \\
\hline NMHC escapamento & 602 & 466 & 1.337 \\
\hline NMHC evaporativa & nd & nd & 1.851 \\
\hline NMHC abastecimento & nd & nd & 53 \\
\hline NMHC total & 602 & 6.564 & 3.241 \\
\hline NOx & 8.311 & 348 & 701 \\
\hline MP & 593 & 757.364 & 140.413 \\
\hline CO ${ }_{2}$ eq & 583.086 & 466 & 3.704 \\
\hline COV & 602 & & \\
\hline
\end{tabular}


A troca de caminhões com mais de 20 anos na Macrometrópole Paulista por veículos novos representa a retirada de 48.126 veículos mais velhos da frota, ou seja, 7.291 caminhões semi-leves, 17.013 caminhões leves, 13.656 caminhões médios, 5.083 caminhões semi-pesados e 5.083 caminhões pesados; totalizando $16 \%$ da frota de caminhões.

Com a troca de caminhões semi-leves, leves, médios, semi-pesados e pesados com mais de 20 anos de idade por veículos novos e com novas tecnologias de controle de emissões, pode-se estimar a redução de 8.311 toneladas de óxidos de nitrogênio $\left(\mathrm{NO}_{\mathrm{x}}\right)$ e 593 toneladas de material particulado (MP). Além da redução da emissão de 583.086 toneladas de dióxido de carbono equivalente $\left(\mathrm{CO}_{2} \mathrm{eq}\right)$, em 2016.

A troca de ônibus urbanos e micro-ônibus com mais de 10 anos na Macrometrópole Paulista por veículos novos representa a retirada de 25.463 veículos mais velhos da frota, ou seja, 16.567 ônibus urbanos e 8.896 micro-ônibus, totalizando $31 \%$ da frota de ônibus. E pode-se estimar a redução de 6.564 toneladas de óxidos de nitrogênio $\left(\mathrm{NO}_{\mathrm{x}}\right)$ e 348 toneladas de material particulado (MP). Além da redução da emissão de dióxido de carbono equivalente $\left(\mathrm{CO}_{2}\right.$ eq) em 757.364 toneladas em 2016.

A retirada de automóveis com mais de 30 anos da frota circulante da Macrometrópole, com o uso de veículos elétricos por exemplo, representa a retirada de 109.254 veículos da frota circulante, sendo 49.700 veículos a gasolina e 59.554 veículos dedicados a etanol, totalizando $1 \%$ da frota de automóveis. Assim como, pode-se estimar a redução de 16.021 toneladas de monóxido de carbono (CO) e 3.704 toneladas de compostos orgânicos voláteis (COV). E a redução da emissão de dióxido de carbono equivalente $\left(\mathrm{CO}_{2}\right.$ eq) em 140.413 toneladas, no ano de 2016.

\subsection{Emissões da Região Metropolitana de São Paulo (RMSP)}

Como apresenta a tabela 1, a região metropolitana de São Paulo é composta por 39 municípios e a frota circulante estimada em 7,32 milhões de veículos, ou seja, cerca de $48 \%$ da frota circulante total do estado de São Paulo.

A tabela 3 apresenta as reduções de emissões de poluentes veiculares no ano de 2016, na região metropolitana de São Paulo. Também foram estimadas as reduções das emissões de monóxido de carbono (CO), hidrocarbonetos não metano de escapamento (NMHC escapamento), hidrocarbonetos não metano evaporativas (NMHC evaporativa), hidrocarbonetos não metano de abastecimento (NMHC abastecimento), hidrocarbonetos não metano totais (NMHC total), óxidos de nitrogênio $\left(\mathrm{NO}_{\mathrm{x}}\right)$, material particulado $(\mathrm{MP})$, dióxido de carbono equivalente $\left(\mathrm{CO}_{2} \mathrm{eq}\right)$ e compostos orgânicos voláteis (COV). 
Tabela 3. Reduções das emissões de poluentes veiculares na região metropolitana de São Paulo em 2016, devido a renovações de frota circulante.

\begin{tabular}{|c|c|c|c|}
\hline & RMSP & RMSP & RMSP \\
\hline poluente (ton) & $\begin{array}{l}\text { Redução das emissões com a } \\
\text { troca de caminhões de mais de } \\
20 \text { anos }\end{array}$ & $\begin{array}{c}\text { Redução das emissões com a } \\
\text { troca de ônibus urbanos e micro- } \\
\text { ônibus com mais de } 10 \text { anos }\end{array}$ & $\begin{array}{l}\text { Redução das emissões com a } \\
\text { retirada de automóveis com } \\
\text { mais de } 30 \text { anos da frota } \\
\text { circulante }\end{array}$ \\
\hline $\mathrm{CO}$ & 702 & 759 & 10.222 \\
\hline NMHC escapamento & 281 & 317 & 853 \\
\hline NMHC evaporativa & nd & nd & 1.178 \\
\hline NMHC abastecimento & nd & nd & 35 \\
\hline NMHC total & 281 & 317 & 2.065 \\
\hline NOx & 3.881 & 4.468 & 449 \\
\hline MP & 277 & 238 & 0,5 \\
\hline $\mathrm{CO}_{2} \mathrm{eq}$ & 235.619 & 313.623 & 88.742 \\
\hline $\mathrm{COV}$ & 281 & 317 & 2.102 \\
\hline
\end{tabular}

A troca de caminhões com mais de 20 anos na região metropolitana de São Paulo por veículos novos representa a retirada de 26.931 veículos mais velhos da frota, ou seja, 4.050 caminhões semi-leves, 9.451 caminhões leves, 7.658 caminhões médios, 2.886 caminhões semi-pesados e 2.886 caminhões pesados, totalizando $15 \%$ da frota de caminhões. Com a troca de caminhões com mais de 20 anos de idade por veículos novos, e com novas tecnologias de controle de emissões, podese estimar a redução de 3.881 toneladas de óxidos de nitrogênio $\left(\mathrm{NO}_{\mathrm{x}}\right)$ e 277 toneladas de material particulado (MP). Além da redução da emissão de 235.619 toneladas de dióxido de carbono equivalente $\left(\mathrm{CO}_{2} \mathrm{eq}\right)$, em 2016.

A troca de ônibus urbanos e micro-ônibus com mais de 10 anos na região metropolitana de São Paulo por veículos novos representa a retirada de 17.249 veículos mais velhos da frota, ou seja, 11.218 ônibus urbanos e 6.031 micro-ônibus, totalizando $31 \%$ da frota de ônibus. E pode-se estimar a redução de 4.468 toneladas de óxidos de nitrogênio $\left(\mathrm{NO}_{\mathrm{x}}\right)$ e 238 toneladas de material particulado (MP). Além da redução da emissão de 313.623 toneladas de dióxido de carbono equivalente $\left(\mathrm{CO}_{2} \mathrm{eq}\right)$, em 2016.

A retirada de automóveis com mais de 30 anos da frota circulante da região metropolitana de São Paulo, com o uso de veículos elétricos por exemplo, representa a retirada de 61.117 veículos da frota circulante, sendo 32.782 veículos a gasolina e 28.936 veículos dedicados a etanol, totalizando $1 \%$ da frota de automóveis. Assim como, pode-se estimar a redução de 10.222 toneladas de monóxido de carbono (CO) e 2.102 toneladas de compostos orgânicos voláteis (COV). Além da redução da emissão de 88.742 toneladas de dióxido de carbono equivalente $\left(\mathrm{CO}_{2} \mathrm{eq}\right)$, em 2016. 


\section{CONCLUSÃO}

A elaboração e a manutenção de inventário de fontes de poluição é fundamental para a correta identificação das fontes e também fornece dados para as políticas públicas de estados, regiões metropolitanas ou mesmo municípios. Os planos e programas de renovação de frotas são instrumentos importantes e podem resultar na remoção de poluentes de origem veicular, além de gases de efeito estufa (GEE), da atmosfera. É crescente o interesse dos governos em diminuir a poluição causada pelos meios de transporte, com incentivos ao aumento da utilização de combustíveis renováveis e/ou ao emprego de veículos elétricos.

Deve-se observar as características próprias de cada categoria de veículos na elaboração de planos/programas de renovação de frota, como por exemplo, com a troca de caminhões e ônibus o foco deve ser a redução de óxidos de nitrogênio $\left(\mathrm{NO}_{\mathrm{x}}\right)$ e de material particulado (MP). E se o enfoque for nos automóveis, a redução se dá principalmente para o monóxido de carbono e os compostos orgânicos voláteis (COV), como indicaram os resultados dos cenários escolhidos neste trabalho.

\section{REFERÊNCIAS}

[1] CETESB. Qualidade do Ar no Estado de São Paulo 2015, São Paulo, SP, 2016a. 165 p. Disponível em: < http://ar.cetesb.sp.gov.br/wpcontent/uploads/sites/37/2013/12/RQAR-2015.pdf>. Acesso em: 10 mai. 2017.

[2] MONKS, P.S. et al. Atmospheric composition change - global and regional air quality, Atmospheric Environment 43, p. 5268-5350, 2009.

[3] SÃO PAULO (Estado). Guia do programa de incentivo à renovação da frota de caminhões. [S.I.: s.n.], [2012]. Disponível em: Plano de Controle de Poluição Veicular do Estado de São Paulo PCPV 2014/2016. Acesso em 05 abr 2017.

[4] SÃO PAULO. Lei $\mathbf{n}^{\circ} \mathbf{1 5 . 8 3 1}$ de 15 de junho de 2015. Autoriza o Poder Executivo a disciplinar nos contratos de concessão a idade média da frota de ônibus, miniônibus e micro-ônibus que opera no Sistema de Transporte Coletivo Urbano de Caráter Metropolitano, e dá providências correlatas. Diário Oficial [do] Estado de São Paulo. Poder Legislativo vol. 125(106). p .8 (2015). Disponível em: <http://www.al.sp.gov.br/norma/?id=174856>Acesso em: 20 jun 2017.

[5] CETESB. Emissões Veiculares no Estado de São Paulo 2016, São Paulo, SP, 2017. 212 p. Disponível em: < http://cetesb.sp.gov.br/veicular/wpcontent/uploads/sites/6/2017/11/EMISS\%C3\%95ES-VEICULARES 09 nov.pdf.

Acesso em: 01 mai. 2018. 
[6] BRASIL. MMA. 10 Inventário nacional de emissões atmosféricas por veículos automotores rodoviários: Relatório Final. [Brasília-DF],2011. Disponível em: <http://www.mma.gov.br/estruturas/163/ publicacao/163 publicacao2707201105520 0.pdf>. Acesso em: 29 ago. 2016.

[7] BRASIL. MMA et al. Inventário nacional de emissões atmosféricas por veículos automotores rodoviários 2013: ano-base 2012: relatório final. [Brasília, DF], $2014 . \quad$ Disponível em: <http://www.mma.gov.br/images/arquivo/80060/Inventario de Emissoes por Veicul os Rodoviarios 2013.pdf>. Acesso em: 29 ago. 2016.

[8] IPCC. National Greenhouse Gas Inventories Programme. 2006 IPCC guidelines for National Greenhouse Gas Inventories. . Edited by Simon Eggleston et al. . Hayama, JP: IGES, 2006. v. 2, n. 3. Disponível em: $<$ http://www.ipcc-

nggip.iges.or.jp/public/2006gl/pdf/2_Volume2/V2_3_Ch3_Mobile_Combustion. pdf> Acesso em: 29 ago. 2016.

[9] IBAMA. Programa de controle da poluição do ar por veículos automotores - PROCONVE (PROGRAMA DE CONTROLE DA POLUIÇÃO DO AR POR VEÍCULOS AUTOMOTORES)/PROMOT/IBAMA. 3a ed. Brasília: Ibama/Diqua, 2011. Disponível em: $<$ http://www.ibama.gov. br/phocadownload/category/4?download=4792\%3Aman ual-portugues >. Acesso em: $01 \mathrm{fev} .2017$.

[10] ANFAVEA. Estatísticas. Dados relativos a 2016: produção, vendas, exportação - produção, vendas e exportação de autoveículos. São Paulo, 2017. Disponível em <http://www.anfavea.com.br/tabelas.html>.Acesso em: 29 ago. 2017.

[11] ABRACICLO. Anuário da indústria brasileira de duas rodas 2015. São Paulo, 2015. Disponível em: <http://www.abraciclo.com.br/anuario-de-2015>. Acesso em: 29 ago. 2016.

[12] ANP. Anuário Estatístico Brasileiro do Petróleo, Gás Natural e Biocombustíveis - Índice. (Anuários dos anos de 2006 a 2015). Disponível em <http://anp.gov.br/?id=661> Acesso em: 29 ago. 2016.

[13] SÃO PAULO (Estado). Secretaria de Energia. Balanço energético do estado de São Paulo - 2015: ano-base - 2014. São Paulo, 2015. (Série Informações Energéticas, 002). Texto bilíngue português-inglês. Disponível em: $<$ http://www.energia.sp.gov.br/a2sitebox/arquivos/documentos/724.pdf > .

Acesso em: 29 ago. 2016.

[14] CETESB. Curvas de intensidade de uso por tipo de veículo automotor da frota da cidade de São Paulo. São Paulo, SP, 2013. 67 p. (Série Relatórios). Disponível em: <http://veicular.cetesb.sp.gov.br/wpcontent/uploads/sites/35/2013/12/curvas-intensidade-uso-veiculos-automotorescidade-sao-paulo.pdf>. Acesso em: 29 ago. 2016. 
[15] DETRAN/SP. Frota de veículos em São Paulo, São Paulo, 2016. Disponível em:http://www.detran.sp.gov.br/wps/portal/portaldetran/detran/estatisticastransito/safrotaveiculos > Acesso em 10 abr. 2017.

[16] EMPLASA. Macrometropole Paulista. Disponível em: <https://www.emplasa.sp.gov.br/>. Acesso em: 16 mai. 2017. 